\title{
First manifestation and evolution of early left ventricular dysfunction in children with Duchenne muscular dystrophy
}

\author{
${ }^{\star 1,2}$ Iulia Rodoman, ${ }^{3}$ Alexandr Dorif, ${ }^{1,2}$ Ina Palii, ${ }^{3}$ Victoria Sacara \\ ${ }^{1}$ Department of Pediatrics, Nicolae Testemitanu State University of Medicine and Pharmacy \\ ${ }^{2}$ Cardiology Unit, ${ }^{3}$ Human Molecular Genetics Laboratory, Institute of Mother and Child \\ Chisinau, the Republic of Moldova
}

The authors' ORCID iDs, academic degrees, and contributions are available at the end of the article

*Corresponding author - Iulia Rodoman, e-mail: iulia.rodoman@gmail.com

Manuscript received October 03, 2021; revised manuscript November 10, 2021; published online November 26, 2021

\begin{abstract}
Background: Standard pediatric cardiology examinations and echocardiography fail to discover when the cardiomyopathy will occur in patient with Duchenne muscular dystrophy (DMD). Noninvasive markers are needed to fill this gap.

Material and methods: This cohort study included a total number of 30 children (21 children (70\%) with DMD and 9 (30\%) healthy children. Blood samples were used for biochemical (level of creatine kinase, creatine kinase-MB, lactate dehydrogenase) and miRNA (presence of miR133a 3p, miR133b 3p, miR206 3p, miR208a 3p, miR208b 3p) analysis. All patients underwent partial conventional echocardiography ECOCG and Speckle Tracking.

Results: The children in the working group presented compared to healthy children: FCC values increased by 15 (71\%) vs 2 (22\%), high levels of CK, $\mathrm{CK}-\mathrm{MB}, \mathrm{LDH}$, which is characteristic for the disease and reflects its stage. Also, there is a decrease in systolic function indicators in the working group: mean FE $59 \pm 3.8 \%$, and GLS: $-16.2 \pm 3.1 \%$. MiRNA analyses confirmed the presence of miR133a 3p, miR133b 3p, miR206 3p, miR208a 3p, miR208b $3 \mathrm{p}$ in both working and control group.

Conclusions: For the first time in the Republic of Moldova, we developed and adapted protocols for RNA extraction from human blood, performing screening of specific miRNA in the serum of patients with DMD and healthy children. Also, altered LV strain notwithstanding a normal or mildly modified LVEF represents an essential viewpoint for prospective pediatric drug trials in DMD-related cardiomyopathy prevention.

Key words: Duchenne muscular dystrophy, miRNA, cardiomyopathy, heart failure, qRT-PCR.
\end{abstract}

\section{Cite this article}

Rodoman I, Dorif A, Palii I, Sacara V. First manifestation and evolution of early left ventricular dysfunction in children with Duchenne muscular dystrophy. Mold Med J. 2021;64(5):62-69. https://doi.org/10.52418/moldovan-med-j.64-5.21.12.

\section{Introduction}

Duchenne muscular dystrophy (DMD) is the most frequent and severe form of progressive muscular dystrophy, with an incidence rate of 6.11 per 100000 population according to the data of the National Center for Reproductive Health and Medical Genetics of the Republic of Moldova $[1,2]$. DMD is a myogenic disorder due to mutations in the dystrophin gene on the Xp21.1 chromosome [3]. Mutations in this gene cause the absence of dystrophin - a component of the cell membrane complex of skeletal, cardiac, and smooth muscle cells and is one of the links between the cytoskeleton and the extracellular matrix [4].

According to literature data, Duchenne myodystrophy has a rapid evolution, with severe disability, approximately at $10-15$ years of age $[5,6]$. In addition, DMD is the second most common lethal human genetic disease globally [7].

Cardiac complications occur in more than $90 \%$ of patients with DMD, with $20 \%$ of them dying. The fibrotic region of cardiomyocytes will gradually stretch, become thinner, and lose contractility, resulting in dilated cardiomyopathy [8].

Studies show that dilated cardiomyopathy is the leading cause of death, so it remains a severe problem that affects survival and requires timely behavior management $[5,9$, 10]. According to the 2017 TREAT-NMD report, 12\% of registered patients (study cohort - 5345 subjects) developed cardiomyopathy [11].

In the case of DMD, cardiomyopathy is usually asymptomatic due to the compensatory mechanisms, which leads to a later manifestation of the symptoms characteristic of heart failure (HF). Therefore, in general, any representation of HF in this group of patients is masked by the severity of myopathic syndrome [12].

So, involvement of the heart in the pathological process in Duchenne myodystrophy has been actively studied since the eighties of the twentieth century [13], the level of early detection of cardiovascular disorders and the prevention of severe complications in patients with hereditary progressive muscular dystrophies remains very low, and the cause of death in most forms of the disease is the involvement of the heart muscle in the pathological process $[14,15]$.

Studies in recent years, aimed at the treatment and support of people with DMD, seek a high-performance treat- 
ment [16]. Current clinical and preclinical therapies are currently based on exon skipping therapies for patients with deletions or duplications of DMD gene exons. Also, there is now a long-term study with Ataluren [17].

So, the prevention of cardiomyopathy holds as one of the most challenging clinical research issues in children with DMD. At the moment, pediatric cardiology examinations, first and foremost echocardiography, fail to discover when and to what level the cardiomyopathy will occur. In addition, most studies have struggled to prove drugs' efficacy on DMD cardiomyopathy incipience and progression rate using conventional echocardiographic measures. The drugs include ACE inhibitors, b-blockers, and corticosteroids. In the modern era, pediatric DMD drug trials require reliable and noninvasive cardiac biomarkers. Unfortunately, currently available tools to evaluate cardiac function may not be precise (blood tests), challenging to perform in pediatric patients (cardiovascular magnetic resonance imaging), or too invasive (myocardial biopsy).

The above exacerbates the need to promote researches related to the early diagnosis of heart problems in DMD to determine the treatment tactics, prevent the development of severe cardiovascular disorders, improve quality, and prolong patients' lives [17].

MicroRNAs implicated in the development of the myopathic process and cardiomyopathy

Non-coding RNAs (ncRNAs), such as miRNAs and long non-coding RNAs, are key regulators of post-transcriptional gene expression and represent promising therapeutic targets and biomarkers for several human diseases, including DMD. In some studies, a role for ncRNA has been suggested in the pathogenesis of muscular dystrophies, although it is still incompletely understood. Long and short non-coding RNAs are differentially expressed in DMD and have a mechanism of action through targeted mRNAs. A subgroup of miRNAs, the so-called myomiRs (miR-133, miR-206, miR-208), have increased values in the serum of patients with DMD and animal models with dystrophin deficiency. Interestingly, myomiRs could be used as biomarkers, as their levels can be corrected after dystrophin restoration in dystrophic mice. Additional scientific evidence demonstrates that nRNAs also play a role in dystrophin expression. Thus, their modulation could represent a potential therapeutic strategy to increase dystrophin levels in combination with other gene therapies [18].

Abnormal serum expression of different miRNAs has been associated with oncological, neurodegenerative, cardiovascular, metabolic, and hereditary diseases, suggesting a potential role as a minimally invasive biomarker [19]. MiRNAs selectively involved in muscle pathways and related to muscle dystrophies have been termed dystromies or myomiRs. These include miR-1, miR-133a, miR-133b, miR31 and miR-206 [20].

MiR-1 and miR-133a are expressed from the exact transcription in skeletal muscle but have different functions [21]. For example, miR-1 promotes myogenesis and ter- minal differentiation, acting on HDAC4 and connexin-43, while miR-133 enhances myoblast proliferation [22].

The same ncRNA also encodes miR-206 and miR-133b. MiR-206 is specific for skeletal muscle, especially oxidative fibers, and is expressed in the proliferation of myoblasts under negative regulation of TGF- $\beta$ and myostatin and positive for myogenin [23-25].

The dystrophin gene is the largest in the human genome, containing 79 exons, and comprises 2.6 million base pairs of the genomic sequence, accounting for about $1.5 \%$ of the entire $\mathrm{X}$ chromosome. Its mutations lead to errors in proteincoding dystrophin.

Defects or absence of dystrophin protein in cardiomyocytes results in DCM by a similar pathway described. Specifically, recent studies have suggested that the absence or mutation of dystrophin disrupts the function of membrane ion channels, especially sarcolemmal stretch-activated channels, which respond to mechanical stress [26-29]. When cardiomyocytes with deficient or mutant dystrophin stretch during ventricular filling, the activated stretching channels do not open properly, increasing calcium influx. High intracellular calcium activates calcium-induced calpain, a group of proteases that will degrade troponin I and compromise cardiomyocyte contraction. The destruction of the Calpain-mediated membrane protein allows more calcium to enter. Finally, chronic calcium overload leads to cardiomyocyte death $[28,29]$. Cardiomyocyte death initiates an inflammatory cascade during which macrophages migrate to remove damaged cells and debris [26-29]. After recruiting macrophages, fibroblasts invade the damaged area and form scar tissue or fibrosis in the heart. Fibrotic tissue is very inflexible compared to normal heart tissue and thus restricts the efficiency of myocardial contraction. Fibrosis begins in the LV wall in DMD and the right ventricular wall in $\mathrm{BMD}$, moving epicardium to endocardium. It spreads progressively over most of the outer half of the ventricular wall. This pattern of fibrosis is unique to dystrophinopathy. The fibrotic region will gradually stretch, become thinner, lose contractility and result in DCM. Dilation of the heart increases left ventricular volume, decreases systolic function, and often leads to mitral valve insufficiency, resulting in decreased cardiac output and hemodynamic decompensation. The cardiac phenotype in each DMD or BMD patient results from the particular type of patient with dystrophin gene mutation; however, the relationship between genotype and phenotype remains elusive [26, 27, 29].

According to recent studies, miRNAs can alter cardiac differentiation: proliferation, maturation, and pathological remodeling responses to stress, injury, and abnormal regulatory expression $[26,28,29]$. Several miRNA matrices have been reported in human cardiac tissue, and several have addressed plasma miRNA profiles in HF [30-32].

Tijsen et al. suggested that miR-423-5p was a diagnostic marker for HF [28]. Others have disclosed classes of miRNAs in the detection of HF. In addition, many studies have identified miRNAs (miR-1, -133, -499, and -208) as signifi- 
cantly elevated in acute myocardial infarction (AMI), and a series of meta-analyses were performed to verify the role of miRNAs in the AMI [33]. However, although numerous reports have been published, the impact of miRNA in CI management is still being discussed.

In the study Noviskas R. [33] miR-1, miR-133, miR145, miR-208, and miR-499 were identified as significant diagnostic and/or prognostic markers in different stages of cardiovascular disease progression. Next miRNAs regulate endothelial function and angiogenesis (miR-1, miR-133), vascular smooth muscle cell differentiation (miR-133, miR145), communication between vascular smooth muscle and endothelial cell for plaque stabilization (miR-145), and regulates endothelial apoptosis and CMNV (miR-1, miR-133, miR-499), differentiates cardiac myocytes (miR1, miR-133, miR-145, miR-208, miR-499) and represses cardiac hypertrophy (miR-133).

\section{Speckle Tracking Echocardiography}

Among the new echocardiography techniques, speckletracking echocardiographic (STE) imaging, or two-dimensional (2D) strain, has emerged as an interesting noninvasive functional biomarker in pediatric cardiology and has also recently been considered in the early detection of DMD cardiomyopathy [34]. STE imaging evaluates myocardial function with a dynamic regionalized analysis of the overall ventricular contraction. This technique measures localized myocardial movements of natural acoustic markers, also called speckles. STE imaging supposedly allows a rapid, precise, and objective segmental and global myocardial function assessment in three longitudinal, radial, and circumferential strain [35]. In addition, several pediatric studies have pointed out the ability of STE analysis to detect preclinical myocardial dysfunction, such as after anthracycline chemotherapy, dilated cardiomyopathy [36], septic shock, ischemic heart disease, and heart transplantation.

Similarly, recent studies with small cohorts or retrospective data suggested that STE strain was altered before the onset of DMD-related cardiomyopathy in animal models and children with DMD [34, 37].

\section{Material and methods}

The research results were obtained in 2019-2021 in a prospective cohort study which took place in the Institute of Mother and Child Care, after enrolling 30 subjects: 21 boys diagnosed with DMD recruited from the Register of Neuromuscular Diseases of the Human Molecular Genetics Laboratory and evaluated in the Cardiology Department of the Pediatrics Department of the Institute of Mother and Child and 9 healthy patients recruited from the Republic of Moldova performed routine analyses within the Specialized Integrated Consultative Department of the Mother and Child Institute.

The study was conducted according to the principles of the Helsinki Declaration (Code of Ethics of the Global Medical Association, amended at the 64th General Assembly of the Global Medical Association, Fortaleza,
Brazil, in October 2013) for experiments involving humans. All participants in this study expressed informed consent, respecting confidentiality. The Research Ethics Committee of Nicolae Testemitanu University of Medicine and Pharmacy issued a favorable opinion within the doctoral scientific project.

The children in the study were assessed according to an individualized examination protocol. Clinical examination was performed with evaluating the following anthropometric parameters: mass, waist, body mass index, hemodynamics (pulse, blood pressure), and paraclinical investigations.

Blood samples and serums taken in the morning by puncture from the ulnar vein after 12 hours of fasting, without exercise before collecting from each subject, were isolated for biochemical and miRNA analysis. Serum samples were used to determine the level of creatine kinase, creatine kinase-MB, lactate dehydrogenase. Increased values of creatine kinase level will be considered > $308 \mathrm{U} / \mathrm{l}$, creatine kinase-MB $>24 \mathrm{U} / \mathrm{l}$, lactate dehydrogenase for age category $0-1$ year $>600 \mathrm{U} / \mathrm{l}, 2-14$ years $>300 \mathrm{U} / \mathrm{l},>15$ years $>225$ $\mathrm{U} / \mathrm{l}$.

The blood samples for miRNA investigation were stored at $-80^{\circ} \mathrm{C}$ until analysis. Then, the presence of miR133a $3 p$, miR133b 3p, miR206 3p, miR208a 3p, miR208b 3p was appreciated.

Molecular methods of nucleic acid analysis took place in 3 steps: total RNA purification using two different kits, control $18 \mathrm{~S}$ rRNA presence by RT-qPCR method, and the last one with an appreciation of specific miRNA presence or absence.

All patients underwent partial echocardiography, echocardiographic measurements with the assessment of systolic function (ejection fraction and global longitudinal strain VS) and LV dimensions after the modified Simpson method [38].

The IBM SPSS Statistics program using parametric and nonparametric criteria was used for statistical processing and descriptive analysis.

\section{Results and discussion}

The DMD group included nine children aged 4-8 years, nine children aged 9-12 years, 3 children older than 12 years with a mean age of $9 \pm 3.7$ years, and the control group included 4,4 , and 1 child respectively but the average age $8 \pm$ 2.5 years.

The children in the workgroup had an average BMI of $17.5 \pm 3.6 \mathrm{~kg} / \mathrm{m}^{2}$, of which one child was impossible to measure due to immobility. On the other hand, the children in the control group showed an average BMI of $17.9 \pm 2.5 \mathrm{~kg} /$ $\mathrm{m}^{2}$.

In the working group, 6 children did not have the data for increased pulse rate. In 15 children, tachycardia was an indirect indicator of stage I impairment in cardiomyopathies with dystrophin deficiency [39]. Of the patients with DMD - 18 children have already started treatment with GCS, three children have refused treatment with Defal. 


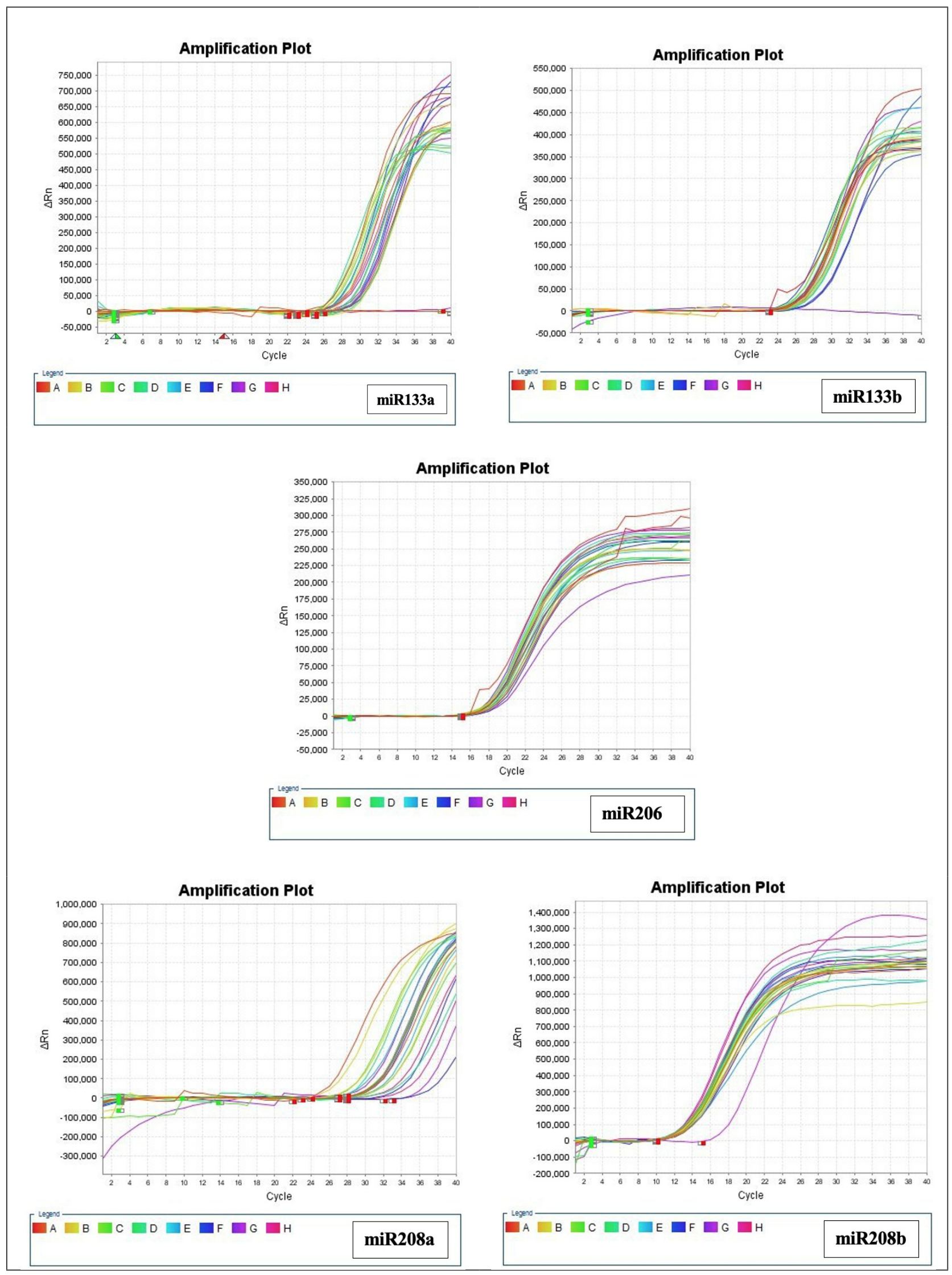

Fig. 1. MiRNA profile in children with Duchenne muscular dystrophy 
Table 1. Clinical characteristics of DMD children included in the study

\begin{tabular}{|c|c|c|}
\hline & Total ammount & $\%$ \\
\hline \multicolumn{3}{|l|}{ Age } \\
\hline 4-8 years & 9 & 42.9 \\
\hline $9-12$ years & 9 & 42.9 \\
\hline$>12$ years & 3 & 14.3 \\
\hline Median age & \multicolumn{2}{|c|}{$9 \pm 3.7$} \\
\hline $\mathrm{BMI}(\mathrm{kg} / \mathrm{m} 2)$ & \multicolumn{2}{|c|}{$17.5 \pm 3.6$} \\
\hline \multicolumn{3}{|c|}{ Cardiovascular symptoms } \\
\hline No cardiovascular symptoms & 11 & 52.4 \\
\hline Exercise dyspnea & 3 & 14.3 \\
\hline Rest dyspnea & 1 & 4.8 \\
\hline Palpitations & 4 & 19.1 \\
\hline Weakness & 3 & 14.3 \\
\hline Tachycardia & 15 & 71.4 \\
\hline \multicolumn{3}{|c|}{ Muscular stage } \\
\hline 0 stage & 2 & 9.5 \\
\hline 1 stage & 16 & 76.1 \\
\hline 2 stages & 1 & 4.8 \\
\hline 3 stages & 2 & 9.5 \\
\hline Glucocorticosteroids & 18 & 85.7 \\
\hline \multicolumn{3}{|c|}{ Analyses } \\
\hline $\mathrm{CK}, \mathrm{U} / \mathrm{I}$ & \multicolumn{2}{|c|}{$10606 \pm 7489$} \\
\hline CK-MB, U/I & \multicolumn{2}{|c|}{$257 \pm 173$} \\
\hline LDH, U/I & \multicolumn{2}{|c|}{$257 \pm 509$} \\
\hline \multicolumn{3}{|c|}{ Echocardiography } \\
\hline $\mathrm{FE}, \%$ & \multicolumn{2}{|c|}{$59 \pm 3.8$} \\
\hline GLS, \% & \multicolumn{2}{|c|}{$-16.2 \pm 3.1$} \\
\hline \multicolumn{3}{|l|}{ Mutation } \\
\hline Deletion & 11 & 52.4 \\
\hline Duplication & 8 & 38.1 \\
\hline Point & 2 & 9.5 \\
\hline
\end{tabular}

The children in the working group presented different stages of the disease: stage 0 (no signs of myopathy) - 2 children, stage 1 (able to walk, impossible to run) - 16 children, stage 2 (impossible to walk) - 1 child, stage 3 (impossible to use hands) -2 children.

In total, the children in the workgroup presented the increased values of creatine kinase levels $-10606 \pm 7489 \mathrm{U} /$ L, CK-MB - $257 \pm 173$ U / L, LDH - $257 \pm 509$ U / L, which is characteristic of children with DMD and reflects the stage of the disease.

Different types of mutation were reported in children diagnosed with DMD - 11 children with deletions, 8 children with duplication, and 2 children with point mutation.

The children in the working group presented data on impaired systolic heart function: mean FE $59 \pm 3.8 \%$, and SGL $-16.2 \pm 3.1 \%$.

The presence or absence of miRNA in serum was confirmed by RT and qPCR using specially developed primers for the project.

MiR133a, miR133b, miR206, miR208a, miR208b were detected in healthy children and children with DMD (fig. $1,2)$.

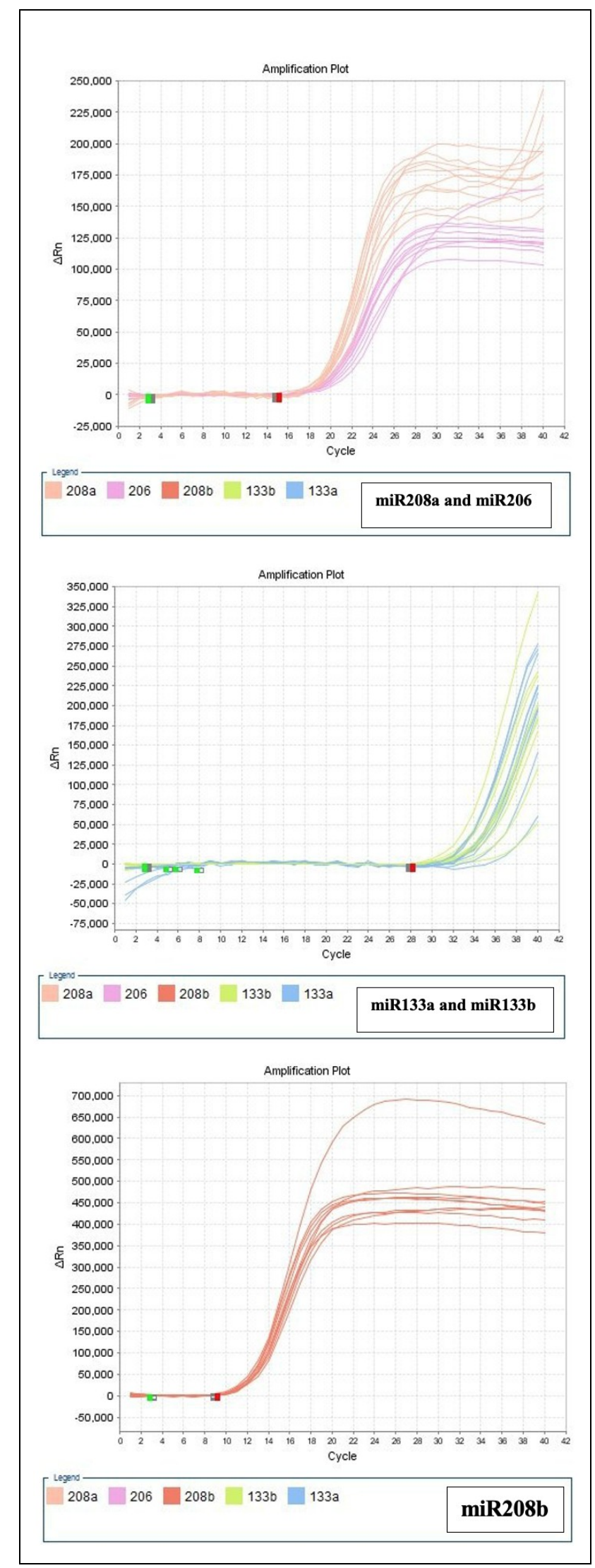

Fig. 2. MiRNA profile in healthy children 


\section{Discussion}

This study was performed among children with DMD presenting no evidence of significant DMD-related cardiomyopathy and without any relevant symptoms of heart failure and with normal or subnormal systolic function on conventional echocardiography.

Global left ventricular 2D strain in boys with DMD was significantly altered with STE analysis before the onset of relevant patterns of cardiomyopathy. This study confirms recently reported preliminary results using evaluation of LV STE strain in patients with DMD. Spurney CF et al. used STE imaging to identify subclinical myocardial dysfunction, showing a decrease in circumferential and longitudinal strain, in a cohort of 33 children with DMD [34]. The retrospective study by Taqatqa $\mathrm{A}$ et al. analyzed circumferential and longitudinal STE strain in 19 children with DMD versus 16 control subjects and found similar results, with an even larger magnitude of difference (global longitudinal STE strain, $18.8 \pm 3.0 \%$ vs $13.6 \pm 5.0 \%$; $\mathrm{p}=.001$ ) [37]

So, our results suggest that speckle-tracking analysis in children with DMD is more accurate than conventional echocardiography to identify areas of myocardial dysfunction and, therefore, early cardiomyopathy onset. This tool could help clinicians identify early cardiac dysfunction in this specific population and begin medical therapy at an early stage of the disease.

Thus, the main result of this study, that is, altered LV strain despite a normal or mildly altered ejection fraction, represents an important perspective for future pediatric drug trials in DMD-related cardiomyopathy prevention. Indeed, reliable and noninvasive biomarkers are necessary for pediatric cardiology trials.

After analyzing several specific data, this paper reported the functions of the most important miRNAs in skeletal muscle tissue and their modification in patients with DMD. Attempts to correlate myomiR levels with clinical parameters in patients with DMD have so far produced controversial results. Several studies have reported a negative correlation between myomiRs levels and the patient's age with $\mathrm{DMD}$, similar to the negative correlation observed with serum creatine kinase.

For example, data on elevated levels of ex-myomiR have been reported in younger patients with DMD (age 2-6 years); this could be explained by the fact that, over this age range, patients with DMD experience a period of average childhood growth (and a walking distance of 6 minutes) that can compensate for the degeneration of myofibers. Consequently, serum myomiR levels were significantly higher in outpatients (mean age 8.2 years) than in nonambulatory patients with DMD (mean age 14 years), probably due to pathological progression and/or higher physical activity. Indeed, exercise in healthy individuals can also increase circulating myomiRs, and serum levels of myomiRs in $m d x$ mice are increased after running exercise. In particular, the magnitude of ex-myomiR growth after acute exercise was found to be smaller than that observed for se- rum creatine kinase, suggesting that measuring ex-myomiR levels is less sensitive to exercise-associated variability than serum creatine kinase [40].

In our study we confirmed the presence of miR133a $3 p$, miR133b 3p, miR206 3p, miR208a 3p, miR208b 3p in both working and control group, and further studies are needed to check their concentration.

Overall, these studies suggest that myomiR levels are influenced by several factors that contribute to the complex pathology of dystrophin-deficient muscle, such as changes in muscle mass, physical activity, and muscle growth and/ or regeneration. As a result, in elderly patients with advanced pathology, serum levels of myomiR may not be able to monitor disease progression (or response to therapy), as a decrease in their levels may indicate either improved muscle function or a reduction in muscle mass. In contrast, higher serum myomiR may suggest an increase in muscle pathology and degeneration, but may also be a consequence of muscle growth and regeneration and/or more severe physical activity, as has been observed in young patients [41, 42].

Based on the above, miRNAs promise both as a biomarker to improve the diagnosis and monitoring of DMD progression and treatment and as therapeutic targets that can be adjusted to relieve early and advanced DMD symptoms. There is a particular need for a susceptible and minimally invasive method to monitor the progression of symptoms and whether a specific treatment successfully ameliorates the outcomes.

Finally, the circumstances in which miRNAs can and should be administered therapeutically require careful analysis. The progression of DMD symptoms is not the same from one patient to another. This, combined with the fact that miRNA expression and function are tissue-specific, means that miRNAs may perform different tasks in each tissue and may not be an appropriate treatment option in all circumstances. Therefore, miRNAs with potentially opposite roles in different tissues should be further examined before considering them as therapeutic targets in treating tissue-specific symptoms observed in specific cases. Ideally, future studies will strive to combine the detection, administration, or inhibition of miRNA with methods such as exon skipping to improve the diagnosis and management of the pathology [43].

Certainly, randomized and standardized studies are needed to establish the predictive value of miRNA. Summarizing the most promising miRNAs and linking them to target genes involved in the development of cardiovascular pathology could also help in future studies [44].

\section{Conclusions}

For the first time, protocols for RNA extraction from human blood have been successfully developed and optimized methods of reverse-transcription and qualitative analysis of miRNAs using a mixture of specific primers in the Human Molecular Genetics Laboratory of the Genetic Center of Excellence. Our screening of miR133a 3p, mir133b 3p, miR206 
3p, miR208a 3p, miR208b 3p in the serum of patients with DMD and healthy children will open a new perspective for the analysis variation of microRNA in the blood collected from patients with DMD and the correlation with their circulating levels and the severity of the disease. In children with DMD, global LV 2D strain was significantly decreased for longitudinal displacements before the onset of DMD-related cardiomyopathy. Moreover, children with DMD presented a significant decrease in global LV longitudinal 2D strain with age and disease stage. Altered LV strain notwithstanding a normal or mildly modified LVEF represents an essential viewpoint for prospective pediatric drug trials in DMD-related cardiomyopathy prevention. Further cohort studies need to be performed to confirm that global longitudinal LV 2D strain represents a reliable surrogate endpoint for heart failure in patients with DMD.

\section{References}

1. D'Amario D, Amodeo A, Adorisio R, Tiziano FD, Leone AM, Perri G, et al. A current approach to heart failure in Duchenne muscular dystrophy. Heart. 2017;103(22):1770-9. doi: 10.1136/heartjnl-2017-311269.

2. Sacară V, Levițchii A, Groppa S, Duca M, Moşin V. Spectrul nozologic al bolilor ereditare ale sistemului nervos şi particularitățile răspîndirii patologiilor neuro-musculare în the Republica Moldova [Nosologic spectrum of hereditary diseases of the nervous system and particulars of neuromuscular pathologies prevalence in Republic of Moldova]. Bul Perinatol. 2012;(3/55):42-9. Romanian.

3. Straub V, Mercuri E. Report on the workshop: meaningful outcome measures for Duchenne muscular dystrophy, London, UK, 30-31 January 2017. Neuromuscul Disord. 2018;28(8):690-701. doi: 10.1016/j. nmd.2018.05.013.

4. Wang M, Birnkrant DJ, Super DM, Jacobs IB, Bahler RC. Progressive left ventricular dysfunction and long-term outcomes in patients with Duchenne muscular dystrophy receiving cardiopulmonary therapies. Open Heart. 2018;5(1):e000783. doi: 10.1136/openhrt-2018-000783.

5. Eagle M, Baudouin SV, Chandler C, Giddings DR, Bullock R, Bushby K. Survival in Duchenne muscular dystrophy: improvements in life expectancy since 1967 and the impact of home nocturnal ventilation. Neuromuscul Disord. 2002;12(10):926-9. doi.org/10.1016/S09608966(02)00140-2.

6. Gorbunova VN, Savelieva-Vasilieva EA, Krasilnikov VV. [Myotonic dystrophy]. In: Gorbunova VN, et al. [Molecular Neuroscience. Part 1. Diseases of the neuromuscular system]. St. Petersburg: Intermedika; 2000. p. 169-181. Russian.

7. Lee TH, Eun LY, Choi JY, Kwon HE, Lee YM, Kim HD, Kang SW. Myocardial atrophy in children with mitochondrial disease and Duchenne muscular dystrophy. Korean J Pediatr. 2014 May;57(5):232-9. doi: 10.3345/kjp.2014.57.5.232.

8. Kaspar RW, Allen HD, Montanaro F. Current understanding and management of dilated cardiomyopathy in Duchenne and Becker muscular dystrophy. J Am Acad Nurse Pract. 2009;21(5):241-9. doi: 10.1111/j.17457599.2009.00404.x.

9. Spurney C, Shimizu R, Morgenroth LP, Kolski H, Gordish-Dressman H, Clemens PR, et al. Cooperative international neuromuscular research group Duchenne natural history study demonstrates insufficient diagnosis and treatment of cardiomyopathy in Duchenne muscular dystrophy. Muscle Nerve. 2014;50(2):250-6. doi: 10.1002/mus.24163.

10. Barber BJ, Andrews JG, Lu Z, West NA, Meaney FJ, Price ET, et al. Oral corticosteroids and onset of cardiomyopathy in Duchenne muscular dystrophy. J Pediatr. 2013;163(4):1080-1084.e1. doi: 10.1016/j. jpeds.2013.05.060.

11. Guergueltcheva V, Chan S, Korngut L, Campbell C, Dai Y, Wang J, et al. Clinical outcomes in Duchenne muscular dystrophy: a study of 5345 patients from the TREAT-NMD DMD Global Database. J Neuromuscul Dis. 2017;4(4):293-306. doi: 10.3233/JND-170280.
12. Groznova OS, Chechuro VV. Lechenie kardiomiopatiei u bol'nykh progressiruiuschimi myshechnymi distrofiiami [Treatment for cardiomyopathies in patients with progressive muscular dystrophies]. Ros Vestn Perinatol Pediatr. 2011;(2):58-62. Russian.

13. Nigro G, Politano L, Nigro V, Petretta VR, Comi LI. Mutation of dystrophin gene and cardiomyopathy. Neuromuscul Disord. 1994;4(4):371-9. doi: 10.1016/0960-8966(94)90073-6.

14. Finsterer J, Stöllberger C, Keller H. Arrhythmia-related workup in hereditary myopathies. J Electrocardiol. 2012;45(4):376-384. doi: 10.1016/j. jelectrocard.2012.02.003.

15. Van Spaendonck-Zwarts KY, Van Rijsingen IAW, Van Den Berg MP, Lekanne Deprez RH, Post JG, Van Mil AM, et al. Genetic analysis in 418 index patients with idiopathic dilated cardiomyopathy: overview of 10 years' experience. Eur J Heart Fail. 2013;15(6):628-36. doi: 10.1093/ eurjhf/hft013.

16. Mendell JR, Rodino-Klapac LR, Sahenk Z, Roush K, Bird L, Lowes LP, et al. Eteplirsen for the treatment of Duchenne muscular dystrophy. Ann Neurol. 2013;74(5):637-47. doi: 10.1002/ana.23982.

17. Bourke JP, Bueser T, Quinlivan R. Interventions for preventing and treating cardiac complications in Duchenne and Becker muscular dystrophy and X-linked dilated cardiomyopathy. Cochrane Database Syst Rev. 2018;10(10):CD009068. doi: 10.1002/14651858.CD009068.pub3.

18. Brusa R, Magri F, Bresolin N, Comi G Pietro, Corti S. Noncoding RNAs in Duchenne and Becker muscular dystrophies : role in pathogenesis and future prognostic and therapeutic perspectives. Cell Mol Life Sci. 2020;77(21):4299-4313. doi: 10.1007/s00018-020-03537-4.

19. Backes C, Meese E, Keller A. Specific miRNA disease biomarkers in blood, serum and plasma: challenges and prospects. Mol Diagn Ther. 2016;20(6):509-18. doi: 10.1007/s40291-016-0221-4.

20. McCarthy J. MicroRNA-206: the skeletal muscle-specific myomiR. Biochim Biophys Acta. 2008;1779(11):682-91. doi: 10.1016/j. bbagrm.2008.03.001.

21. Eisenberg I, Eran A, Nishino I, Moggio M, Lamperti C, Amato AA, et al. Distinctive patterns of microRNA expression in primary muscular disorders. Proc Natl Acad Sci USA. 2007;104(43):17016-21. doi: 10.1073/ pnas.0708115104.

22. Chen JF, Mandel EM, Thomson JM, Wu Q, Callis TE, Hammond SM, et al. The role of microRNA-1 and microRNA-133 in skeletal muscle proliferation and differentiation. Nat Genet. 2006;38(2):228-33. doi: $10.1038 / \mathrm{ng} 1725$.

23. Amirouche A, Jahnke VE, Lunde JA, Koulmann N, Freyssenet DG, Jasmin BJ. Muscle-specific microRNA-206 targets multiple components in dystrophic skeletal muscle representing beneficial adaptations. Am J Physiol Cell Physiol. 2017;312(3):C209-21. doi: 10.1152/ ajpcell.00185.2016.

24. Liu N, Williams AH, Maxeiner JM, Bezprozvannaya S, Shelton JM, Richardson JA, et al. microRNA-206 promotes skeletal muscle regeneration and delays progression of Duchenne muscular dystrophy in mice. J Clin Invest. 2012;122(6):2054-65. doi: 10.1172/JCI62656.

25. Yuasa K, Hagiwara Y, Ando M, Nakamura A, Takeda S, Hijikata T. MicroRNA-206 is highly expressed in newly formed muscle fibers: implications regarding potential for muscle regeneration and maturation in muscular dystrophy. Cell Struct Funct. 2008;33(22):163-9. doi: $10.1247 /$ csf.08022.

26. Bronze-da-Rocha E. MicroRNAs expression profiles in cardiovascular diseases. Biomed Res Int. 2014;2014:985408. doi: 10.1155/2014/985408.

27. Creemers EE, Tijsen AJ, Pinto YM. Circulating microRNAs: novel biomarkers and extracellular communicators in cardiovascular disease? Circ Res. 2012;110(3):483-95. doi: 10.1161/CIRCRESAHA.111.247452.

28. De Rosa S, Curcio A, Indolfi C. Emerging role of microRNAs in cardiovascular diseases. Circ J. 2014;78(3):567-75. doi: 10.1253/circj.cj-140086.

29. De Rosa R, De Rosa S, Leistner D, Boeckel J-N, Keller T, Fichtlscherer $\mathrm{S}$, et al. Transcoronary concentration gradient of microRNA-133a and outcome in patients with coronary artery disease. Am J Cardiol. 2017;120(1):15-24. doi: 10.1016/j.amjcard.2017.03.264.

30. Li S, Zhu J, Zhang W, Chen Y, Zhang K, Popescu LM, et al. Signature microRNA expression profile of essential hypertension and its novel link to human cytomegalovirus infection. Circulation. 2011;124(2):175-84. doi: 10.1161/CIRCULATIONAHA.110.012237 
31. Thum T, Galuppo P, Wolf C, Fiedler J, Kneitz S, van Laake LW, et al. MicroRNAs in the human heart. Circulation. 2007;116(3):258-67. doi: 10.1161/CIRCULATIONAHA.107.687947.

32. Adachi T, Nakanishi M, Otsuka Y, Nishimura K, Hirokawa G, Goto Y, et al. Plasma MicroRNA 499 as a biomarker of acute myocardial infarction. Clin Chem. 2010;56(7):1183-5. doi: 10.1373/clinchem.2010.144121.

33. Navickas R, Gal D, Laucevičius A, Taparauskaitė A, Zdanytė M, Holvoet P. Identifying circulating microRNAs as biomarkers of cardiovascular disease: a systematic review. Cardiovasc Res. 2016;111(4):322-37. doi: $10.1093 / \mathrm{cvr} / \mathrm{cvw} 174$.

34. Spurney CF, McCaffrey FM, Cnaan A, Morgenroth LP, Ghelani SJ, Gordish-Dressman $\mathrm{H}$, et al. Feasibility and reproducibility of echocardiographic measures in children with muscular dystrophies. J Am Soc Echocardiogr. 2015;28(8):999-1008. doi: 10.1016/j.echo.2015.03.003.

35. Cameli M, Mandoli GE, Lisi E, Ibrahim A, Incampo E, Buccoliero G, et al. Left atrial, ventricular and atrio-ventricular strain in patients with subclinical heart dysfunction. Int J Cardiovasc Imaging. 2019;35(2):24958. doi: 10.1007/s10554-018-1461-7.

36. Friedberg MK, Slorach C. Relation between left ventricular regional radial function and radial wall motion abnormalities using two-dimensional speckle tracking in children with idiopathic dilated cardiomyopathy. Am J Cardiol. 2008;102(3):335-9. doi: 10.1016/j.amjcard.2008.03.064.

37. Taqatqa A, Bokowski J, Al-Kubaisi M, Khalil A, Miranda C, Alaksham H, et al. The use of speckle tracking echocardiography for early detection of myocardial dysfunction in patients with Duchenne muscular dystrophy Pediatr Cardiol. 2016;37(8):1422-8. doi: 10.1007/s00246-016-1451-2.

38. Vdovenko DV, Libis RA. [The myocardial deformation and diastolic function of the left ventricle in patients with heart failure with preserved left ventricular ejection fraction]. Arter Hypertens (Russian Fed). 2018;24(1):74-80. Russian. https://doi.org/10.18705/1607419X-2018-24-1-74-80.

39. Fayssoil A, Abasse S, Silverston K. Cardiac involvement classification and therapeutic management in patients with Duchenne muscular dystrophy. J Neuromuscul Dis. 2017;4(1):17-23. doi: 10.3233/JND-160194.

40. Nguyen-Tran D-H, Hait NC, Sperber H, Qi J, Fischer K, Ieronimakis $\mathrm{N}$, et al. Molecular mechanism of sphingosine-1-phosphate action in Duchenne muscular dystrophy. Dis Model Mech. 2014;7(1):41-54. doi: 10.1242/dmm.013631.

41. Kim HK, Lee YS, Sivaprasad U, Malhotra A, Dutta A. Muscle-specific microRNA miR-206 promotes muscle differentiation. J Cell Biol. 2006;174(5):677-87. doi: 10.1083/jcb.200603008.

42. Llano-Diez M, Ortez CI, Gay JA, Álvarez-Cabado L, Jou C, Medina J, et al. Digital PCR quantification of miR-30c and miR-181a as serum biomarkers for Duchenne muscular dystrophy. Neuromuscul Disord. 2017;27(1):15-23. doi: 10.1016/j.nmd.2016.11.003.

43. Hrach HC, Mangone M. miRNA profiling for early detection and treatment of Duchenne muscular dystrophy. Int J Mol Sci. 2019;20(18):4638. doi: 10.3390/ijms20184638.

\section{Authors' ORCID iDs and academic degrees}

Iulia Rodoman, MD, Master in Molecular Biology, PhD Applicant - https://orcid.org/0000-0003-0982-2281

Alexandr Dorif, Master in Chemistry and Molecular Biology - https://orcid.org/0000-0003-4269-4066

Ina Palii, MD, PhD, Professor - https://orcid.org/0000-0002-4320-2951

Victoria Sacara, MD, PhD, Associate Professor - https://orcid.org/0000-0001-9200-0494

\section{Authors' contribution}

IR conducted a literature review, collected the data, wrote the first manuscript, and interpreted the statistical data. IP conceptualized the idea and critically revised the manuscript. AD and VS conducted/performed the laboratory work, revised and approved the final text.

\section{Funding}

The study was supported by Nicolae Testemitanu State University of Medicine and Pharmacy. The authors are independent and take responsibility for the integrity of the data and the accuracy of the data analysis.

\section{Ethics approval and consent to participate}

The study was approved by the Research Ethics Committee of Nicolae Testemitanu State University of Medicine and Pharmacy (protocol No 6 of October 30,2019). Informed consent was obtained from all study participants.

\section{Conflict of Interests}

The authors have no conflict of interests to declare. 